OPEN ACCESS

Edited by:

John Varlotto,

University of Massachusetts

Medical Center, USA

Reviewed by:

Paul Stephen Rava,

UMass Memorial Medical Center,

USA

Nitin Ohri,

Albert Einstein College of Medicine,

USA

*Correspondence:

Joel S. Greenberger

greenbergerjs@upmc.edu

Specialty section: This article was submitted to

Radiation Oncology,

a section of the journal

Frontiers in Oncology

Received: 05 April 2016 Accepted: 05 January 2017 Published: 23 January 2017

Citation: Bernard ME, Glaser SM, Gill BS, Beriwal S, Heron DE, Luketich JD, Friedland DM, Socinski MA and Greenberger JS (2017) Results of a Single Institution Experience with Dose-Escalated Chemoradiation for

Locally Advanced Unresectable Non-Small Cell Lung Cancer. Front. Oncol. 7:1.

doi: 10.3389/fonc.2017.00001

\section{Results of a Single Institution Experience with Dose-Escalated Chemoradiation for Locally Advanced Unresectable Non-Small Cell Lung Cancer}

\author{
Mark E. Bernard', Scott M. Glaser', Beant S. Gill', Sushil Beriwal', Dwight E. Heron', \\ James D. Luketich ${ }^{2}$, David M. Friedland ${ }^{3}$, Mark A. Socinski ${ }^{3}$ and Joel S. Greenberger ${ }^{1 *}$ \\ 'Department of Radiation Oncology, University of Pittsburgh Cancer Institute, Pittsburgh, PA, USA, ${ }^{2}$ Department of Thoracic \\ Surgery, University of Pittsburgh Medical Center, Pittsburgh, PA, USA, ${ }^{3}$ Division of Hematology/Oncology, Department of \\ Medicine, University of Pittsburgh Medical Center, Pittsburgh, PA, USA
}

Background: We determined factors associated with morbidity and outcomes of a series of non-small cell lung cancer (NSCLC) patients treated with dose-escalated chemoradiotherapy at the University of Pittsburgh Lung Cancer Program.

Methods and materials: The records of 170 stage III NSCLC patients treated with definitive intent were retrospectively reviewed. All patients received four-dimensional CT simulation scan and had respiratory gating if tumor movement exceeded $5 \mathrm{~mm}$. Overall survival (OS), locoregional control (LRC), and freedom from distant metastasis (FFDM) were calculated using log-rank and Cox regression analysis.

Results: For the present series of patients, median follow-up was 36.6 months, median survival 27.4 months, and the 2- and 4-year OS was 56.0 and $30.7 \%$, respectively. The 4-year LRC and FFDM were 43.9 and $40.7 \%$, respectively. No benefit was associated with irradiation doses above 66 Gy in OS ( $p=0.586)$, LRC $(p=0.440)$, or FFDM $(p=0.230)$. On univariate analysis, variables associated with worse survival included: clinical stage IIIB $(p=0.037)$, planning target volume (PTV) over $450 \mathrm{cc}(p<0.001)$, heart $V_{30}$ over $40 \%$ $(p=-0.048)$, and esophageal mean dose over $20 \%(p=0.024), V_{5}(p=-0.015)$, and $\vee_{60}(p=-0.011)$. On multivariable analysis, PTV above 450 cc (52.2 vs. 25.3 months, $p<0.001)$ and esophageal $V_{60}>20 \%$ (43.8 vs. 21.3 months, $p=-0.01$ ) were associated with lower survival. Grade 2 or higher acute lung toxicity and esophagitis were detected in 9.5 and $59.7 \%$, respectively of patients. Grade 2 or higher acute lung toxicity was reduced if lung $V_{5}$ was $\leq 65$ (7.4 vs. 23.8\%, $p=0.03$ ). Grade 2 or higher acute esophagitis was reduced if $\mathrm{V}_{60} \leq 20 \%$ (62 vs. 81.3\%, $p=0.018$ ). The use of intensity-modulated radiation therapy was more frequent in stage IIIB compared to stage IIIA patients (56.5 vs. 39.5\%, $p=0.048$ ) and was associated with a higher lung $V_{5}$ and $V_{10}$.

Conclusion: The outcomes of a program of dose-escalated chemoradiotherapy for unresectable stage IIIA and IIIB NSCLC patients were consistent with other studies and showed no benefit to radiation doses above 66 Gy. Furthermore, maintaining low esophageal $\bigvee_{60}$ and lung $V_{5}$ were associated with lower morbidity and mortality.

Keywords: NSCLC, dose escalation, chemoradiation, esophagitis, pneumonitis 


\section{INTRODUCTION}

The optimal chemoradiation therapy management of locally advanced non-small cell lung cancer (NSCLC) has been a subject of great interest (1). Even with current aggressive multi-modality treatment protocols, the clinical outcomes remain suboptimal (2). Previous clinical trials have established the superiority of concurrent chemoradiation using radiation doses between 60 and $66 \mathrm{~Gy}$ and revealed median survival times of 16-18 months (3-5). Dose-escalation protocols in Phase II clinical trials revealed the feasibility of radiation doses up to $74 \mathrm{~Gy}$ and suggested some increase in median survival to 26 months (6). Advances in radiation therapy techniques such as intensity-modulated radiation therapy (IMRT), three-dimensional conformal radiation therapy (3D-CRT), motion management, and attention to normal tissue dose parameters allowed dose escalation in some studies $(7,8)$. Radiation dose-escalation trials were evaluated for improved locoregional control (LRC) and overall survival (OS).

A recent clinical Trial from the RTOG (RTOG 0617) for stage IIIA/B NSCLC (2) was initiated to randomize radiation dose groups to cohorts of $60 \mathrm{~Gy}$ compared to $74 \mathrm{~Gy}$ each with similar concurrent chemotherapy. The 74-Gy arm showed no benefit and was associated with a survival detriment. Both arms had the same LRC, distant metastasis rate and measured toxicity; however, further analysis showed that the use of IMRT was associated with better patient reported quality of life, and also that improved baseline pretreatment QOL was predictive of survival (9). Other parameters influencing survival included low heart dose, low esophageal morbidity, and smaller planning target volume (PTV). Although, it is important to note, the lack of pretreatment quality assurance from a central review has called the outcomes in question, especially when it comes to delineating normal structures such as the heart $(10,11)$.

We now report the results of this single institution experience with definitive chemoradiation for stage IIIA and IIIB NSCLC and compare outcomes for patients treated with 3D-CRT compared to patients treated with IMRT.

\section{MATERIALS AND METHODS}

\section{Patient Population}

We carried out a retrospective study using the criteria established by the American Joint Committee on Cancer (AJCC) seventh edition for patients with Stage IIIA and IIIB NSCLC. All patients were treated with definitive intent over the interval 2001-2013. All patients were determined to be unresectable by either: multiple node positivity, contralateral or supraclavicular lymph nodes, or tumor invasion of adjacent organs.

Patient medical records were de-identified and analyzed with ethical approval by the University of Pittsburgh Institutional Review Board (IRB \#PRO13020306). The review was done with compliance to our ethic standards. All patients received daily radiotherapy fractions using a megavoltage linear accelerator with photon energy above $6 \mathrm{MV}$, and either IMRT or 3D-CRT. Radiation therapy was delivered concurrently with dual agent chemotherapy. All patients received four-dimensional CT
(4D-CT) scan to assess target motion at time of simulation. Respiratory gating was included in daily treatments if tumor movement during simulation was greater than $5 \mathrm{~mm}$ in any direction (12).

\section{Staging}

The staging system for NSCLC changed during the years of the study, therefore, we used the AJCC seventh staging edition as a standard for all patients. Patients were staged using PET/CT of the chest, abdomen, and pelvis, brain MRI, mediastinal lymph node sampling, and biopsy of both primary cancer and multiple mediastinal lymph nodes.

\section{Dosimetry Parameters}

In general, the normal esophagus was defined as being from the cricopharyngeus muscle to the gastroesophageal junction and the lung volume including the bilateral lungs from the apex chest apex to the diaphragm while subtracting out the PTV. These were mostly already created using our treatment plan software and we also used paper charts to assist with determine dosimetry values. In general our goals were V20 for lung $<30 \%$, mean esophagus dose less than or equal to $35 \mathrm{~Gy}$ and cord dose less than or equal to $45 \mathrm{~Gy}$. Heart dose varied based on tumor location. For IMRT we also added V $5<60 \%$ and V10 $<40 \%$ constraints for lung. In our early experience, patients were treated with fixed-field IMRT and after expanded to both rapid arc and fixed-field IMRT.

\section{Statistical Analysis}

LRC, freedom from distant metastasis (FFDM), and OS were primary outcome measures, and were calculated using log-rank and Cox regression analysis from time of diagnosis. Locoregional control was defined as lack of progression of clinical disease, seen on follow-up imaging or biopsy of the radiation therapy treatment volume for primary and regional lymph nodes. Acute toxicity was evaluated using binomial regression and late toxicity evaluated using Cox regression, $t$-test, ANOVA, binomial regression, and linear regression analysis. Each outcome measurement was correlated to dosimetric variables. Multivariable analysis (MVA) was performed for each factor found to be significant on unvariant analysis $(p \leq 0.05)$. Statistical analysis was performed using IBM SPSS Statistics Version 23.

\section{RESULTS}

\section{Patient Demographics}

There were 597 patients with clinical stage IIIA or IIIB NSCLC in the UPCI database over the interval 2001 to 2013. Patients treated with palliative intent $(n=296)$ were excluded as were those receiving only surgical management $(n=28)$. Radiotherapy patients not treated with concurrent chemotherapy $(n=39)$ were excluded. The remaining cohort of 213 patients was evaluated. Forty-three patients were lost to follow-up defined as no follow-up from treatment. Median follow-up of the cohort of 170 patients was 22 months and is shown in Table 1. The Interquartile Range (IQR) was 8.9-39.6. Median follow-up was 
TABLE 1 | Baseline characteristics for entire cohort $(n=170)$.

\begin{tabular}{|c|c|}
\hline Patient variables & Results \\
\hline $\begin{array}{l}\text { Age } \\
\text { Median and range (years) }\end{array}$ & $67(38-91)$ \\
\hline $\begin{array}{l}\text { Gender } \\
\text { Male } \\
\text { Female }\end{array}$ & $\begin{array}{r}111(65.3 \%) \\
59(34.7 \%)\end{array}$ \\
\hline $\begin{array}{l}\text { Race } \\
\text { Caucasian } \\
\text { African-American } \\
\text { NOS/other }\end{array}$ & $\begin{array}{r}137(80.6 \%) \\
33(19.4 \%)\end{array}$ \\
\hline $\begin{array}{l}\text { Histology } \\
\text { Adenocarcinoma } \\
\text { Squamous cell } \\
\text { Large cell } \\
\text { Mixed } \\
\text { NSCLC/NOS }\end{array}$ & $\begin{array}{r}77(45.3 \%) \\
54(31.8 \%) \\
10(5.9 \%) \\
2(1.2 \%) \\
27(15.9 \%)\end{array}$ \\
\hline $\begin{array}{l}\text { Stage } \\
\text { T4N0 } \\
\text { T3N1 } \\
\text { T4N1 } \\
\text { T0N2 } \\
\text { T1N2 } \\
\text { T2N2 } \\
\text { T3N2 } \\
\text { T4N2 } \\
\text { T0N3 } \\
\text { T1N3 } \\
\text { T2N3 } \\
\text { T3N3 } \\
\text { T4N3 }\end{array}$ & $\begin{array}{r}10(5.9 \%) \\
3(1.8 \%) \\
3(1.8 \%) \\
8(4.7 \%) \\
21(12.4 \%) \\
36(21.2 \%) \\
16(9.4 \%) \\
20(11.8 \%) \\
8(4.7 \%) \\
11(6.5 \%) \\
17(10 \%) \\
7(4.1 \%) \\
10(5.9 \%)\end{array}$ \\
\hline $\begin{array}{l}\text { Stage } \\
\text { IIIA } \\
\text { IIIB }\end{array}$ & $\begin{array}{l}97(57.1 \%) \\
73(42.9 \%)\end{array}$ \\
\hline $\begin{array}{l}\text { Chemotherapy } \\
\text { Carboplatin paclitaxel } \\
\text { Cisplatin and etoposide } \\
\text { Carboplatin and protein-bound paclitaxel } \\
\text { Cisplatin and gemcitabine } \\
\text { Carboplatin and pemetrexed } \\
\text { Carboplatin and etoposide } \\
\text { Carboplatin and docetaxel } \\
\text { Cisplatin and docetaxel }\end{array}$ & $\begin{array}{r}150(88.2 \%) \\
5(2.9 \%) \\
1(0.6 \%) \\
1(0.6 \%) \\
2(1.2 \%) \\
5(2.9 \%) \\
3(1.8 \%) \\
3(1.8 \%)\end{array}$ \\
\hline $\begin{array}{l}\text { Volumes } \\
\text { Median GTV (cc) } \\
\text { Median PTV (cc) }\end{array}$ & $\begin{array}{r}84(4-586) \\
338(43-1303)\end{array}$ \\
\hline $\begin{array}{l}\text { Technique } \\
\text { 3D-RT } \\
\text { IMRT } \\
\text { N/A }\end{array}$ & $\begin{array}{r}119(70 \%) \\
46(27.1 \%) \\
5(2.9 \%)\end{array}$ \\
\hline $\begin{array}{l}\text { Simulation } \\
\text { No gating } \\
\text { Gating } \\
\text { N/A }\end{array}$ & $\begin{array}{r}127(74.7 \%) \\
23(13.5 \%) \\
20(11.8 \%)\end{array}$ \\
\hline $\begin{array}{l}\text { Dose (Gy) } \\
\text { Median and range }\end{array}$ & $72(54-84)$ \\
\hline $\begin{array}{l}\text { Dose ranges (Gy) } \\
54-66 \\
67-70 \\
71-74 \\
75-80 \\
81-84\end{array}$ & $\begin{array}{r}41(24.1 \%) \\
32(18.8 \%) \\
51(30 \%) \\
45(26.5 \%) \\
1(0.6 \%)\end{array}$ \\
\hline
\end{tabular}

GTV, gross tumor volume; NA, not available; NSCLC, non-small cell lung cancer; NOS, not otherwise specified; 3D-CRT, three-dimensional conformal radiation therapy; IMRT, intensity-modulated radiation therapy; PTV, planning target volume.
36.6 months (IQR, 26.6-63.7) for the subset of patients still living.

\section{Treatment and Dosimetric Evaluation}

All patients were treated with concurrent chemoradiation, median radiation dose was 72 Gy (IQR, 68-77). The treatment volume and doses had inhomogeneity corrections. IMRT was used in $27.1 \%$. All patients received a $4 \mathrm{D}-\mathrm{CT}$ simulation scan, and $13.5 \%$ required respiratory gating. Concurrent carboplatin and paclitaxel were the dual agents in $88.2 \%$ of patients.

\section{Overall Survival}

The median survival of the entire group was 27.4 months. There was a 2 - and 4 -year OS of 56.0 and $30.7 \%$, respectively. On univariate analysis decreased survival was detected in the subset of patients with: (1) stage IIIB ( $p=0.037)$, (2) PTV $>450 \mathrm{cc}$ $(p<0.001)$, (3) heart $\mathrm{V}_{30}>40 \%(p=0.048)$, (4) esophageal mean dose of $>20 \%(p=0.024)$, (5) esophageal $V_{5}>60 \%$ $(p=0.015)$, and (6) esophageal $\mathrm{V}_{60}>20 \%(p=0.011)$. On multivariate analysis decreased survival was detected in patients with a large PTV ( $\geq 450$ vs. $<450$ cc; 52.2 vs. 25.3 months, $p<0.001)$. Esophageal volumes of $\mathrm{V}_{60}$ that were over $20 \%$ were also associated with reduced survival $\left(\mathrm{V}_{60} \leq 20\right.$ vs. $>20 ; 43.8$ vs. 21.3 months, $p=0.01$ ). Radiation dose above $66 \mathrm{~Gy}$ was not associated with improved OS $(p=0.586)$. Statistical analysis is shown in Table 2.

\section{Locoregional Control}

The 2-and 4-year LRC for the entire group was 54.4 and $43.9 \%$, respectively. On univariate analysis, large PTV was associated with a reduced LRC $[\leq 450$ vs. $>450 \mathrm{cc}, \mathrm{HR}=1.86 ; 95 \%$ confidence interval (CI) (1.03-3.36), $p=0.039$ ]. Radiation dose above 66 Gy was not associated with increased LRC $(p=0.440)$.

\section{Freedom from Distant Metastasis}

The percentage of 2- and 4-year FFDM was 54.4 and 40.7\%, respectively, for the entire group. On univariate analysis, higher radiation therapy doses $(p=0.041)$ and PTV $>450 \mathrm{cc}(p=0.004)$ were each associated with reduced FFDM. On multivariate analysis, PTV above $450 \mathrm{cc}[\leq 450$ vs. $>450 \mathrm{cc}, \mathrm{HR}=2.15,95 \%$ CI (1.27-3.62), $p=0.004]$ was associated with reduced FFDM. A radiation dose above 66 Gy was not associated with an improved $\operatorname{FFDM}(p=0.230)$.

\section{Factors Influencing Toxicity}

In the present series, the median value of mean lung dose was 15.2 Gy (IQR, 13-18 Gy) and median lung $\mathrm{V}_{20}$ was 26\% (IQR $21-31 \%)$. There was grade 2 or higher acute lung toxicity detected in $9.5 \%$ of patients. On univariate analysis, the use of 3D-CRT $(p=0.036)$ and $\mathrm{V}_{5} \leq 65(p=0.036)$ were associated with a lower rate of pneumonitis. On multivariate analysis, lung $V_{5} \leq 65$ was associated with a decreased acute grade 2 or higher lung toxicity ( 7.4 vs. $23.8 \%, p=0.027$ ). The incidence of 1 -year and 2 -year late grade $3+$ pneumonitis was 1.2 and $2.1 \%$, respectively. There were no detectable univariate factors that predicted for late grade 3 or higher pneumonitis. 
TABLE 2 | Univariate and multivariable analysis (MVA) for overall survival (OS), LRC, and freedom from distant metastasis (FFDM).

\begin{tabular}{|c|c|c|c|}
\hline & os & Locoregional control & FFDM \\
\hline Age $\leq 60$ & $p=0.373$ & $\mathrm{HR}=0.614(0.368-1.024), p=0.062$ & $p=0.261$ \\
\hline Gender & $p=0.166$ & $p=0.408$ & $p=0.686$ \\
\hline Race & $p=0.742$ & $p=0.540$ & $p=0.926$ \\
\hline Histology & $p=0.155$ & $p=0.904$ & $p=0.562$ \\
\hline IIIA vs. IIIB & $\begin{array}{l}\text { HR }=1.465 ; 95 \% \text { confidence interval }(\mathrm{Cl}) \\
(1.024-2.096), p=0.037\end{array}$ & $p=0.467$ & $\begin{array}{l}\mathrm{HR}=0.598,95 \% \mathrm{Cl} \\
(0.374-0.956), p=0.032\end{array}$ \\
\hline RT dose (continuous) & $p=0.761$ & $p=0.706$ & 0.511 \\
\hline$\leq 66$ vs. $>66$ Gy & $p=0.586$ & $p=0.440$ & $p=0.230$ \\
\hline 3D vs. IMRT & $p=0.427$ & $p=0.991$ & 0.964 \\
\hline $\mathrm{PTV}_{450 \mathrm{cc}}$ & $\mathrm{HR}=2.305,95 \% \mathrm{Cl}(1.478-3.596), p<0.001$ & $\begin{array}{l}\mathrm{HR}=1.860 ; 95 \% \mathrm{Cl}(1.031-3.356) \\
p=0.039\end{array}$ & $\begin{array}{l}\mathrm{HR}=2.149,95 \% \mathrm{Cl} \\
(1.274-3.624), p=0.004\end{array}$ \\
\hline \multicolumn{4}{|l|}{ Lung } \\
\hline Mean & $p=0.402$ & - & - \\
\hline$V_{5}$ & $p=0.584$ & - & - \\
\hline$V_{10}$ & $p=0.519$ & - & - \\
\hline$V_{20}$ & $p=0.474$ & - & - \\
\hline$V_{30}$ & $p=0.186$ & - & - \\
\hline \multicolumn{4}{|l|}{ Heart } \\
\hline Maximum & $p=0.242$ & - & - \\
\hline Mean & $p=0.091$ & - & - \\
\hline$V_{30} \leq 40$ & $\mathrm{HR}=1.836,95 \% \mathrm{Cl}(1.005-3.353), p=0.048$ & - & - \\
\hline \multicolumn{4}{|l|}{ Esophageal } \\
\hline Max & $p=0.408$ & - & - \\
\hline Mean $\leq 20$ & $\mathrm{HR}=2.146,95 \% \mathrm{Cl}(1.105-4.167), p=0.024$ & - & - \\
\hline$V_{5} \leq 60$ & $\mathrm{HR}=1.017,95 \% \mathrm{Cl}(1.003-1.030), p=0.015$ & - & - \\
\hline$V_{60} \leq 20$ & $\mathrm{HR}=1.758,95 \% \mathrm{Cl}(1.135-2.721), p=0.011$ & - & - \\
\hline \multicolumn{4}{|l|}{ MVA } \\
\hline $\mathrm{PTV}_{450 \mathrm{cc}}$ & 52.2 vs. 25.3 months, $p<0.001$ & $\begin{array}{l}\mathrm{HR}=1.860 ; 95 \% \mathrm{Cl}(1.031-3.356) \\
p=0.039\end{array}$ & $\begin{array}{l}\mathrm{HR}=2.149,95 \% \mathrm{Cl} \\
(1.274-3.624), p=0.004\end{array}$ \\
\hline Esophageal $V_{60} \leq 20$ & 43.8 vs. 21.3 months, $p=0.01$ & - & - \\
\hline
\end{tabular}

3D-CRT, three-dimensional conformal radiation therapy; IMRT, intensity-modulated radiation therapy; PTV, planning target volume; RT, radiation therapy.

The median value for the mean esophageal dose in the group was $28 \mathrm{~Gy}$ in the present study (IQR, 21-33 Gy). The median esophageal $\mathrm{V}_{60}$ was $16 \%$ (IQR, 3-27\%). Acute grade 2 or higher esophagitis was detected $59.7 \%$ of patients. On univariate analysis, a lower radiation therapy dose as a continuous variable $(p=-0.041)$ and esophageal $\mathrm{V}_{60} \leq 20 \%(p=-0.027)$ were associated with lower rates of acute grade 2 or higher esophagitis. On multivariate analysis, esophageal $\mathrm{V}_{60} \leq 20 \%$ was associated with a lower rate of acute grade 2 or higher esophagitis (62 vs. $81.3 \%, p=0.018$ ). We observed late 1-year and 2 -year grade $3+$ esophagitis in 4.5 and $6.5 \%$ of patients, respectively. There was no detectable univariate factor that predicted late grade 3 or higher esophagitis (Table 3).

\section{Utilization and Outcomes of 3D-CRT vs. IMRT}

We compared factors that were associated with the radiation oncologist's choice of 3D-CRT vs. IMRT for radiotherapy management. We found no detectable difference by patient age $(p=0.095)$, gender $(p=0.072)$, race $(p=0.340)$, histology $(p=0.752)$, RT dose $(p=0.131)$, respiratory gating $(p=0.105)$, or PTV $(p=0.459)$. IMRT use was higher in IIIB patients than in IIIA patients ( 56.5 vs. $39.5 \%, p=0.048$ ). For IIIB compared to IIIA patients, IMRT was associated with a higher lung $\mathrm{V}_{5}$ ( 37 vs. $57 \%, p=0.001)$ and $V_{10}(30$ vs. $43 \%, p=0.002)$. Compared
TABLE 3 | Univariate and multivariable analysis (MVA) for acute toxicity.

\begin{tabular}{|c|c|c|}
\hline & $\begin{array}{l}\text { Acute grade } 2+\text { lung } \\
\text { toxicity }\end{array}$ & Acute $2+$ esophagitis \\
\hline 3D-CRT vs. IMRT & $\begin{array}{l}H R=3.181(1.079-9.384) \\
p=0.036\end{array}$ & $p=0.086$ \\
\hline RT dose & $p=0.626$ & $\begin{array}{l}\mathrm{HR}=1.060,95 \% \\
\text { confidence Interval }(\mathrm{Cl}) \\
(1.002-1.120, p=0.041)\end{array}$ \\
\hline PTV & $p=0.720$ & $p=0.951$ \\
\hline \multicolumn{3}{|l|}{ Lung } \\
\hline Mean & $p=0.893$ & - \\
\hline$V_{5} \leq 65$ & $\begin{array}{l}\mathrm{HR}=3.884,95 \% \mathrm{Cl} \\
(1.096-13.767), p=0.036\end{array}$ & - \\
\hline$V_{10}$ & $p=0.377$ & - \\
\hline$V_{20}$ & $p=0.345$ & - \\
\hline $\mathrm{V}_{30}$ & $p=0.895$ & - \\
\hline \multicolumn{3}{|l|}{ Esophagus } \\
\hline Max & - & 0.743 \\
\hline Mean & - & 0.077 \\
\hline$V_{5}$ & - & 0.208 \\
\hline$V_{60} \leq 20$ & - & $\begin{array}{l}\mathrm{HR}=2.2697,95 \% \mathrm{Cl} \\
(1.115-6.340), p=0.027\end{array}$ \\
\hline \multicolumn{3}{|l|}{ MVA } \\
\hline $\begin{array}{l}V_{5} \leq 65 \\
\text { Esophageal } V_{60} \leq 20\end{array}$ & 7.4 vs. $23.8 \%, p=0.027$ & $\overline{6}$ vs v. $81.3 \%, p=0.018$ \\
\hline
\end{tabular}

3D-CRT, three-dimensional conformal radiation therapy; IMRT, intensity-modulated radiation therapy; PTV, planning target volume, $R T$, radiation therapy. 
TABLE 4 | Dosimetric outcomes for 3D-CRT vs. intensity-modulated radiation therapy (IMRT) in IIIA and IIIB non-small cell lung cancer patients.

\begin{tabular}{|c|c|c|c|}
\hline & & Mean & $p$-Value \\
\hline \multicolumn{4}{|c|}{ Clinical IIIA } \\
\hline \multicolumn{4}{|l|}{ Lung } \\
\hline \multirow[t]{2}{*}{ Mean } & $3 D$ & 15 & 0.491 \\
\hline & $\mathrm{IMRT}$ & 16 & \\
\hline \multirow[t]{2}{*}{$V_{5}$} & $3 \mathrm{D}$ & 37 & 0.001 \\
\hline & $\mathrm{IMRT}$ & 57 & \\
\hline \multirow[t]{2}{*}{$V_{10}$} & $3 D$ & 30 & 0.002 \\
\hline & IMRT & 43 & \\
\hline \multirow[t]{2}{*}{$V_{20}$} & $3 \mathrm{D}$ & 23 & 0.195 \\
\hline & IMRT & 26 & \\
\hline \multirow[t]{2}{*}{$V_{30}$} & $3 \mathrm{D}$ & 19 & 0.758 \\
\hline & $\mathrm{IMRT}$ & 19 & \\
\hline \multicolumn{4}{|l|}{ Heart } \\
\hline \multirow[t]{2}{*}{ Maximum } & $3 \mathrm{D}$ & 56 & 0.068 \\
\hline & $\mathrm{IMRT}$ & 68 & \\
\hline \multirow[t]{2}{*}{ Mean } & $3 D$ & 12 & 0.430 \\
\hline & IMRT & 14 & \\
\hline \multirow[t]{2}{*}{$\mathrm{V}_{30}$} & $3 \mathrm{D}$ & 15 & 0.716 \\
\hline & IMRT & 17 & \\
\hline \multicolumn{4}{|c|}{ Esophagus } \\
\hline \multirow[t]{2}{*}{ Max } & $3 D$ & 69 & 0.049 \\
\hline & IMRT & 74 & \\
\hline \multirow[t]{2}{*}{ Mean } & $3 \mathrm{D}$ & 25 & 0.528 \\
\hline & IMRT & 27 & \\
\hline \multirow[t]{2}{*}{$V_{5}$} & $3 D$ & 57 & 0.288 \\
\hline & IMRT & 61 & \\
\hline \multirow[t]{2}{*}{$V_{60}$} & $3 D$ & 14 & 0.785 \\
\hline & IMRT & 15 & \\
\hline \multicolumn{4}{|c|}{ Clinical IIIB } \\
\hline \multicolumn{4}{|l|}{ Lung } \\
\hline \multirow[t]{2}{*}{ Mean } & $3 D$ & 17 & 0.774 \\
\hline & IMRT & 17 & \\
\hline \multirow[t]{2}{*}{$V_{5}$} & $3 D$ & 45 & 0.009 \\
\hline & $\mathrm{IMRT}$ & 59 & \\
\hline$V_{10}$ & $3 \mathrm{D}$ & 33 & 0.004 \\
\hline & $\mathrm{IMRT}$ & 45 & \\
\hline$V_{20}$ & $3 D$ & 28 & 0.413 \\
\hline & IMRT & 30 & \\
\hline$V_{30}$ & $3 D$ & 23 & 0.240 \\
\hline & IMRT & 21 & \\
\hline Heart & & & \\
\hline Maximum & $3 \mathrm{D}$ & 71 & 0.026 \\
\hline & IMRT & 53 & \\
\hline Mean & $3 D$ & 17 & 0.133 \\
\hline & IMRT & 12 & \\
\hline$V_{30}$ & $3 \mathrm{D}$ & 24 & 0.054 \\
\hline & IMRT & 13 & \\
\hline Esophagu & & & \\
\hline Max & $3 D$ & 74 & 0.452 \\
\hline & IMRT & 72 & \\
\hline Mean & $3 D$ & 34 & 0.739 \\
\hline & $\mathrm{IMRT}$ & 33 & \\
\hline$V_{5}$ & $3 D$ & 66 & 0.087 \\
\hline
\end{tabular}

to patients treated with 3D-CRT, there was a lower esophageal mean dose for IMRT patients (69 vs. 74\%, $p=0.049$ ) (Table 4). The median survival for IIIB patients treated with IMRT was higher than those treated with 3D-CRT, but the data did not reach statistical significance (19.0 vs. 26.1 months, $p=0.429$ ). IMRT use was also associated with improved survival for IIIA patients, but did not reach statistical significance (28.7 vs. 42.3 months, $p=0.418$ ).

\section{DISCUSSION}

Despite advances in delivery techniques for radiation therapy, patients with locally advanced NSCLC have displayed suboptimal outcomes, and median survival remains between 15 and 26 months $(2,13)$. Dose-escalation protocols for radiation therapy doses above 60 Gy showed a benefit, but also revealed increased toxicities (14). The addition of concurrent chemotherapy to 60 Gy radiation resulted in further improved survival (3-5). While some phase II studies showed the feasibility of doseescalated chemoradiation therapy with higher survival outcomes, the recent RTOG 0617 study did not confirm a benefit to the use of higher radiation dose $(2,6)$. We compared the RTOG 0617 results with those of our single institution series at UPCI.

The median survival for the present cohort of 170 evaluable NSCLC stage IIIA and IIIB patients was 27.4 months. This value is comparable to the median survival reported in the recent RTOG 0617 trial. In both studies, better staging with PET/CT leading to stage migration and improvements in treatment delivery and better supportive care may have accounted for the improvement in survival (2).

The median radiation dose delivered to patients in our single institution study was $72 \mathrm{~Gy}$. We determined the value of dose escalation by comparing those patients treated to doses above 66 Gy with those receiving doses below 66 Gy. This cut-off value was based upon prior clinical trials comparing sequential to concurrent chemoradiation (3-5). Prior trials showed that concurrent, dual agent, platinum-based chemotherapy was more effective than use of sequential single drugs in chemoradiation protocols (3-5). We found no benefit for those patients treated above $66 \mathrm{~Gy}$. We also found no benefit if the radiation dose was analyzed as a continuous variable. Therefore, we conclude that our data correlate with the results of RTOG 0617 showing no benefit to radiation dose escalation above $66 \mathrm{~Gy}$.

The present analysis revealed that PTV volumes of NSCLC tumor above $450 \mathrm{cc}$ were associated with a lower OS, LRC, and FFDM, again confirming the results presented in RTOG 0617 (2). Another clinical trial, which is a randomized phase II program, which evaluates adaptive planning in stage IIIA/B NSCLC patients for dose escalation, RTOG 1106, is ongoing. The control arm in this new study will receive $50 \mathrm{~Gy}$, then continuing to $60 \mathrm{~Gy}$ after an interim PET/CT scan. The experimental arm will receive 46.2 Gy, then PET/CT scan evaluation, then use adaptive doseescalation ranges using the FDG-PET/CT scan up to a total dose of $80.4 \mathrm{~Gy}$.

Our study revealed new information on toxicity of chemoradiotherapy of NSCLC. Acute grade 2 or higher lung toxicity in $9.5 \%$ patients was associated with a median lung $\mathrm{V}_{20}$ of $26 \mathrm{~Gy}$. The data correlate well with a prior study showing that $\mathrm{V}_{20}$ values between 22 and 31 Gy led to an $8 \%$ pneumonitis rate (8). 
In this prior study (8), $42 \%$ of patients received chemotherapy (concurrent or sequential). In our study, the low rate of pneumonitis with high dose concurrent chemoradiation was likely attributable to $4 \mathrm{D}-\mathrm{CT}$ simulation and the pre-screening of patients with tumor movement to include respiratory gating in their treatment program. Lower rates of lung toxicity were also detected in patients, where there was $\mathrm{V}_{5} \leq 65 \%$. A prior study (15), showed that $\mathrm{V}_{5} \leq 42 \%$ did indeed correlate with a lower rate of acute pneumonitis for NSCLC patients treated with concurrent chemoradiation (15). A review of 220 esophageal cancer patients (16) also treated with radiation alone showed that $V_{5} \leq 60 \%$ correlated with lower rates of acute pneumonitis. We conclude that mean lung dose and lung $\mathrm{V}_{20}$ are the standard dosimetric parameters for predicting pneumonitis; however, we suggest that more attention should be given to the low dose volumes when treating patients with IMRT.

Esophagitis remains a serious complication of chemoradiotherapy of NSCLC. Esophageal grade 2 or higher toxicity rate was observed in $59.7 \%$ of our patients. This result was consistent with the combined grade 2 or higher esophagitis rate of the $74 \mathrm{~Gy}$ arm (43\%) in the RTOG 0617 study (2). Keeping the esophageal $\mathrm{V}_{60} \leq 20 \%$ correlated with lower frequency of detection of acute grade 2 or higher esophagitis. A retrospective analysis of another series of 109 NSCLC patients treated with concurrent chemoradiation showed the esophageal $\mathrm{V}_{60}$ correlated with higher rates of acute esophagitis (17). In yet another study, the threshold dose of 58 Gy predicted acute grade 3 or higher esophageal toxicity (18). Therefore, there is a consensus that the magnitude of the esophageal volume receiving more than 40-50 Gy correlates with the severity of acute esophagitis $(19,20)$. Our results support efforts to ensure that as much of the esophagus as possible should be spared from the high-dose region. We will plan on incorporating our knowledge of the esophageal $\mathrm{V}_{60}$ this into our treatment planning for stage III patients treated with definitive chemoradiation.

The RTOG 0617 study showed that the use of IMRT did improve the QOL in NSCLC patients and reduced rates of grade 3 pneumonitis. In addition, there was an increased likelihood of completing adjuvant chemotherapy $(2,9)$. We found that IMRT use was greater for IIIB patients, likely due to the requirement for coverage of supraclavicular and contralateral mediastinal disease, while achieving acceptable $\mathrm{V}_{20}$ volumes (mean, 30\%) and attempting to still reduce lung toxicity. IMRT treatment plans decreased the esophageal $\mathrm{V}_{60}$ volume and the maximum heart dose. There was a trend for IMRT treatment plans to decrease the heart $V_{30}$ volume, a parameter associated with survival outcomes on univariate analysis, but not multivariate analysis. A lowered heart $\mathrm{V}_{30}$ was also associated with improved survival outcomes in the RTOG 0617 study (2).

There was no statistically significant increase in survival for IIIA or IIIB patients treated with IMRT vs. 3D-CRT, although median survival times were different. In a secondary analysis of the data in RTOG 0617, the high-dose arm was associated with a lower patient reported QOL at 3 months, and baseline pretreatment QOL was predictive of survival (9). IMRT use was associated with a less deterioration of QOL compared to patients receiving 3D-CRT. We were unable to associate use of IMRT with a possible survival benefit, although a trend in this direction was apparent. A larger study with a more balanced distribution between uses of IMRT compared to 3D-RT may result in a statistically significant difference.

Patients treated with IMRT did not show a decreased rate of acute esophagitis or pneumonitis. This result may have been attributable to a higher usage of IMRT for patients with IIIB disease, and the need for larger treatment volumes. Two retrospective reviews of NSCLC patients showed decreased rates of pneumonitis with use of IMRT when compared to 3D-CRT for $\operatorname{NSCLC}(7,21)$. Radiation therapy planning comparing 3D-CRT to IMRT showed that IMRT also lead to a 50\% relative reduction in predicted esophageal complications (22).

We analyzed our data using Kaplan-Meier plots, and this method revealed separation of the LRC and FFDM curves from OS (Figure 1). The data suggest that patients in our cohort may have died from causes other than local or distant recurrence of NSCLC. Since patients with aerodigestive cancers have a 3-5\% yearly risk of a second aerodigestive primary cancer, we recommend that radiation oncologists ensure that long-term follow-up visits include screening for second cancers.

There were limitations to our retrospective analysis of NSCLC patients, including: (1) single institution retrospective review, (2) lack of a prospective randomized trial, and (3) limited follow-up interval. These factors might have led to both overestimating the primary outcomes and underestimating late toxicity. We also have a limited number of patients, and thus, our reports should be compared with other single institution reports and randomized control trials. We are additionally limited since we did not have electronic records for most of our patients and, therefore, may lead unreported events. Last, our dosimetry data are based on

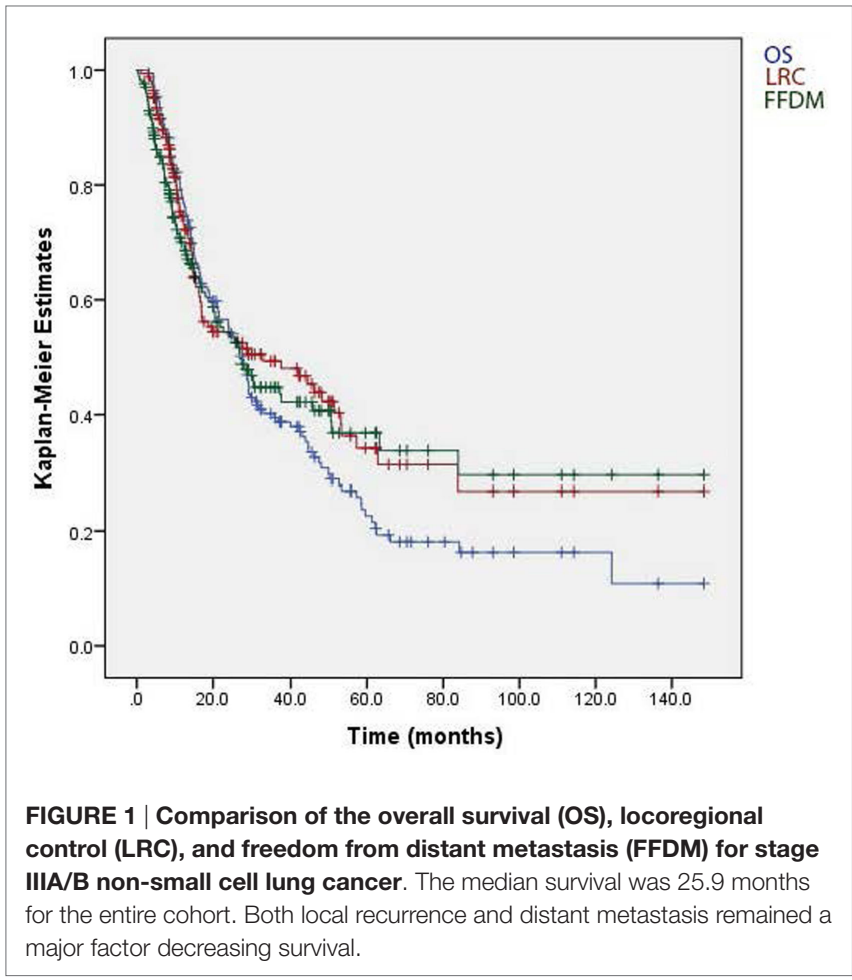


treating physicians who may have used different treatment considerations. We have overcome this issue by implementation of clinical pathways to guide our physicians and to have a more uniform criterion for care.

In a retrospective review of stage IIIA/B, NSCLC patients at UPCI larger PTV volumes and esophageal $\mathrm{V}_{60}>20 \%$ were associated with poorer survival. Acute grade 2 or higher lung toxicity was lower in the $\mathrm{V}_{5} \leq 65 \%$ group and acute grade 2 plus esophagitis was lower in the $\mathrm{V}_{60} \leq 20 \%$ group. We recommend that patients with unresectable stage IIIA and IIIB NSCLC, who require radiotherapy be treated to doses not exceeding $66 \mathrm{~Gy}$.

\section{AUTHOR CONTRIBUTIONS}

MB performed the retrospective review of the data analyzed in the manuscript and performed the majority of the statistics and was responsible for drafting and editing the manuscript. SG assisted with statistics and drafting of the manuscript. BG assisted in

\section{REFERENCES}

1. Rodrigues G, Choy H, Bradley J, Rosenzweig KE, Bogart J, Curran WJ Jr, et al. Definitive radiation therapy in locally-advanced non-small cell lung cancer: executive summary of an American society for radiation oncology (ASTRO) evidence-based clinical practice guideline. Pract Radiat Oncol (2015) 5(3):141-8. doi:10.1016/j.prro.2015.02.012

2. Bradley JD, Paulus R, Komaki R, Masters G, Blumenschein G, Schild S, et al. Standard-dose versus high-dose conformal radiotherapy with concurrent and consolidation carboplatin plus paclitaxel with or without cetuximab for patients with stage IIIA or IIIB non-small-cell lung cancer (RTOG 0617): a randomized, two-by-two factorial p. Lancet Oncol (2015) 16(2):187-99. doi:10.1016/S1470-2045(14)71207-0

3. Curran WJ, Paulus R, Langer CJ, Komaki R, Lee JS, Hauser S, et al. Sequential vs. concurrent chemoradiation for stage III non-small cell lung cancer: randomized phase III trial RTOG 9410. J Natl Cancer Inst (2011) 103(19):1452-60. doi:10.1093/jnci/djr325

4. Fournel P, Robinet G, Thomas P, Souquet PJ, Léna H, Vergnenégre A, et al. Randomized phase III trial of sequential chemoradiotherapy compared with concurrent chemoradiotherapy in locally-advanced non-small-cell lung cancer: Groupe Lyon-Saint-Etienne d'Oncologie Thoracique-Groupe Français de Pneumo-Cancérologie NPC 95-01 study. J Clin Oncol (2005) 23(25):5910-7. doi:10.1200/JCO.2005.03.070

5. Zatloukal P, Petruzelka L, Zemanova M, Havel L, Janku F, Judas L, et al. Concurrent versus sequential chemoradiotherapy with cisplatin and vinorelbine in locally-advanced non-small cell lung cancer: a randomized study. Lung Cancer (2004) 46(1):87-98. doi:10.1016/j.lungcan.2004.03.004

6. Patel SR, Jenkins J, Papadopolous N, Havel L, Janku F, Judas L, et al. Dose-escalating conformal thoracic radiation therapy with induction and concurrent carboplatin/paclitaxel in unresectable stage IIIA/B nonsmall cell lung carcinoma: a modified phase I/II trial. Cancer (2001) 92(5):1213-23. doi:10.1002/1097-0142(20010901)92:5<1213:AID-CNCR1440>3.0.CO;2-0

7. Liao ZX, Komaki RR, Thames HD, Liu HH, Tucker SL, Mohan R, et al. Influence of technologic advances on outcomes in patients with unresectable, locally-advanced non-small-cell lung cancer receiving concomitant chemoradiotherapy. Int J Radiat Oncol Biol Phys (2010) 76(3):775-81. doi:10.1016/ j.ijrobp.2009.02.032

8. Graham MV, Purdy JA, Emami B, Harms W, Bosch W, Lockett MA, et al. Clinical dose-volume histogram analysis for pneumonitis after 3D treatment for non-small cell lung cancer (NSCLC). Int J Radiat Oncol Biol Phys (1999) 45(2):323-9. doi:10.1016/S0360-3016(99)00183-2

9. Movsas B, Hu C, Sloan J, Bradley J, Komaki R, Masters G, et al. Quality of life analysis of a radiation dose-escalation study of patients with non-small-cell lung cancer: a secondary analysis of the radiation therapy oncology group drafting the manuscript, statistical analysis, and literature review. SB oversaw drafting of the manuscript and edits and outlined the message and topic. DH assisted in drafting the manuscript and providing edits. JL provided edits concerning surgical outcomes. DF and MS reviewed the manuscript for medical oncology. JG led the team and edited the manuscript.

\section{ACKNOWLEDGMENTS}

The authors would like to acknowledge Karlotta Ashby and Karen Holeva for ensuring ethical compliance and providing them with the ability to conduct this retrospective review.

\section{FUNDING}

This study was funded by the Department of Radiation Oncology of UPCI.

0617 randomized clinical trial. JAMA Oncol (2016) 2(3):359-67. doi:10.1001/ jamaoncol.2015.3969

10. Gong Y, Gore EM, Bar-Ad V, Wheatley M, Kong F, Yu J, et al. Variation of cardiac contours using different heart definitions for NSCLC patients enrolled on RTOG 0617. Int J Radiat Oncol Biol Phys (2014) 90(1):s739. doi:10.1016/ j.ijrobp.2014.05.2150

11. FitzGerald TJ, Bishop-Jodoin M, Followill DS, Galvin J, Knopp MV, Michalski JM, et al. Imaging and data acquisition in clinical trials for radiation therapy. Int J Radiat Oncol Biol Phys (2016) 94(2):404-11. doi:10.1016/j.ijrobp.2015. 10.028

12. Keall PJ, Mageras GS, Balter JM, Emery RS, Forster KM, Jiang SB, et al. The management of respiratory motion in radiation oncology report of AAPM task group 76. Med Phys (2006) 33:3874-900. doi:10.1118/ 1.2349696

13. Albain KS, Crowley JJ, Turrisi AT, Gandara DR, Farrar WB, Clark JI, et al. Concurrent cisplatin, etoposide, and chest radiotherapy in pathologic stage IIIB non-small-cell lung cancer: a Southwest oncology group phase II study, SWOG 9019. J Clin Oncol (2002) 20(16):3454-60. doi:10.1200/ JCO.2002.03.055

14. Perez CA, Stanley K, Rubin P, Gandara DR, Farrar WB, Clark JI, et al. A prospective randomized study of various irradiation doses and fractionation schedules in the treatment of lnoperable non-oat-cell carcinoma of the lung: RTOG 7301. Cancer (1980) 45(11):2744-53. doi:10.1002/10970142(19800601)45:11<2744:AID-CNCR2820451108>3.0.CO;2-U

15. Wang S, Liao Z, Wei X, Liu HH, Tucker SL, Hu CS, et al. Analysis of clinical and dosimetric factors associated with treatment-related pneumonitis (TRP) in patients with non-small-cell lung cancer (NSCLC) treated with concurrent chemotherapy and three-dimensional conformal radiotherapy (3D-CRT). Int J Radiat Oncol Biol Phys (2006) 66(5):1399-407. doi:10.1016/ j.ijrobp.2006.07.1337

16. Shen WB, Zhu SC, Gao HM, Li YM, Liu ZK, Li J, et al. [Low dose volume histogram analysis of the lungs in prediction of acute radiation pneumonitis in patients with esophageal cancer treated with three-dimensional conformal radiotherapy]. Zhonghua Zhong Liu Za Zhi (2013) 35(1):45-9. doi:10.3760/ cma.j.issn.0253-3766.2013.01.010

17. Caglar HB, Othus M, Allen AM. Esophagus in-field: a new predictor for esophagitis. Radiother Oncol (2010) 97(1):48-53. doi:10.1016/j.radonc.2010. 07.024

18. Singh AK, Lockett MA, Bradley JD. Predictors of radiation-induced esophageal toxicity in patients with non-small-cell lung cancer treated with three-dimensional conformal radiotherapy. Int J Radiat Oncol (2003) 55(2):337-41. doi:10.1016/S0360-3016(02)03937-8

19. Bernard ME, Clump DA, Lalonde R, Beriwal S. Radiation therapy for locally-advanced lung cancer. Transl Cancer Res (2015) 4(4):356-71. doi:10.3978/ j.issn.2218-676X.2015.08.03 
20. Werner-Wasik M, Yorke E, Deasy J, Nam J, Marks LB. Radiation dose-volume effects in the esophagus. Int J Radiat Oncol Biol Phys (2010) 76(3 Suppl):86-93. doi:10.1016/j.ijrobp.2009.05.070

21. Yom SS, Liao Z, Liu HH, Tucker SL, Hu CS, Wei X, et al. Initial evaluation of treatment-related pneumonitis in advanced-stage non-small-cell lung cancer patients treated with concurrent chemotherapy and intensity-modulated radiotherapy. Int J Radiat Oncol Biol Phys (2007) 68(1):94-102. doi:10.1016/ j.ijrobp.2006.12.031

22. Grills IS, Yan D, Martinez AA, Vicini FA, Wong JW, Kestin LL. Potential for reduced toxicity and dose escalation in the treatment of inoperable non-small-cell lung cancer: a comparison of intensity-modulated radiation therapy (IMRT), 3D conformal radiation, and elective nodal irradiation. Int J Radiat Oncol Biol Phys (2003) 57(3):875-90. doi:10.1016/S0360-3016(03) 01359-2
Conflict of Interest Statement: The authors declare that the research was conducted in the absence of any commercial or financial relationships that could be construed as a potential conflict of interest.

The reviewer PR and handling Editor declared their shared affiliation, and the handling Editor states that the process nevertheless met the standards of a fair and objective review.

Copyright (ㄷ 2017 Bernard, Glaser, Gill, Beriwal, Heron, Luketich, Friedland, Socinski and Greenberger. This is an open-access article distributed under the terms of the Creative Commons Attribution License (CC BY). The use, distribution or reproduction in other forums is permitted, provided the original author(s) or licensor are credited and that the original publication in this journal is cited, in accordance with accepted academic practice. No use, distribution or reproduction is permitted which does not comply with these terms. 